\title{
¿Ética sin metafísica? \\ El contractualismo moral de Thomas Scanlon
}

\author{
FAVIOLA Rivera CASTRO \\ Instituto de Investigaciones Filosóficas \\ Universidad Nacional Autónoma de México \\ faviolarivera@gmail.com \\ faviola@filosoficas.unam.mx
}

Resumen: En Lo que nos debemos unos a otros. ¿Qué significa ser moral?, Thomas Scanlon ofrece una postura sobre el contenido y la base normativa de "la moralidad de lo correcto y lo incorrecto", la cual trata, de acuerdo con él, de lo que nos debemos unos a otros. Mi objetivo es examinar las razones por las cuales Scanlon sostiene que su postura no es metafísica sino práctica. Rastreo el significado de "práctico" en algunos escritos de John Rawls y de Kant, y sostengo que, en realidad, la metafísica de la moral no es necesariamente incompatible con el carácter práctico de esta última. En mi opinión, el rechazo de la metafísica por parte de Scanlon está motivado por su concepción no categórica de la moral.

Palabras clave: ética, contractualismo moral, Scanlon, metafísica

\begin{abstract}
In What We Owe to Each Other, Thomas Scanlon offers an account of both the content and the normative basis of the morality of right and wrong, by which he means that part of morality concerned with what we owe to each other. I examine the reasons why Scanlon maintains that his account is not metaphysical but practical. I trace the meaning of "practical" back to some of John Rawls's writings as well as Kant's, and I hold that, in fact, moral metaphysics is not incompatible with morality's practical character. In my view, Scanlon's rejection of metaphysics is motivated by his conception of morality as being not categorical.
\end{abstract}

Key words: ethics, moral contractualism, Scanlon, metaphysics

El rechazo de la metafísica se ha vuelto un lugar común entre los filósofos morales, incluso entre autores neokantianos como John Rawls y Jürgen Habermas. Rawls afirma que los objetivos de la filosofía política deben ser prácticos y no metafísicos. ${ }^{1}$ Habermas sostiene que el papel de la filosofía debe ser "modesto" en comparación con los proyectos fundacionales de Kant y de Hegel, y que dicha modestia conlleva un "adiós a la metafísica". ${ }^{2}$ En el contexto de la filosofía política contemporánea, el adiós a la metafísica ha tenido la virtud de encaminar las

${ }^{1}$ J. Rawls, "Justice as Fairness: Political not Metaphysical" (1985).

${ }^{2}$ J. Habermas, Pensamiento postmetafísico (1988); id., "Remarks on Discourse Ethics", en Justification and Application (1991).

Diánoia, volumen LII, número 59 (noviembre 2007): pp. 43-65. 
discusiones hacia problemas de contenido. Rawls, en particular, se centró en preguntas tales como qué principios de justicia deben regir las instituciones sociales básicas en una sociedad democrática, cómo sería posible lograr acuerdos políticos a pesar del pluralismo, y qué principios deben regir las relaciones entre los estados. La actitud antimetafísica ha alejado a la filosofía política de preguntas fundacionales para orientarla hacia los problemas políticos de las sociedades contemporáneas. ${ }^{3}$

Si bien este cambio de orientación ha resultado ser muy fructífero en la filosofía política, no queda claro que sea apropiado extenderlo a la filosofía moral que se ocupa de los principios y valores que deben guiarnos en las relaciones interpersonales no gobernadas por las instituciones políticas. Si bien no existe un acuerdo sobre qué sea la metafísica, por "metafísica de la moral" podemos entender, en un sentido amplio, una concepción sobre la naturaleza y el origen de los conceptos morales. En un sentido más estricto y tradicional, la "metafísica" de la moral se ha ocupado de la fundamentación racional de los valores morales. En el sentido amplio, las investigaciones de David Hume y de J.S. Mill sobre el origen de los valores morales serían metafísicas. En un sentido estricto, sólo las éticas racionalistas podrían tener una parte metafísica. Por ello, cuando se habla del rechazo de la metafísica en filosofía moral usualmente se trata del rechazo de proyectos racionalistas fundacionalistas, como el racionalismo dogmático que postula un orden metafísico de hechos morales o el fundacionalismo kantiano. Sin embargo, en filosofía política, el rechazo a la metafísica, además de dirigirse en contra de tesis fundacionalistas, con frecuencia también se dirige en contra de las investigaciones sobre la naturaleza y el origen de los principios y los valores políticos, es decir, se dirige en contra de las investigaciones metafísicas entendidas en su sentido más amplio. Si bien esta estrategia, en la filosofía política, de dejar de lado las cuestiones filosóficas generales ha facilitado la articulación de las bases para posibles acuerdos políticos, no es nada obvio por qué en filosofía moral tendría que abandonarse la investigación sobre la fundamentación de los valores morales, o bien, de manera más amplia, por qué tendría que abandonarse la investigación sobre la naturaleza y el origen de los valores morales.

En este artículo me voy a ocupar de un caso particular de postura antimetafísica en filosofía moral, a saber, la defendida por Thomas

${ }^{3}$ Para una crítica de esta actitud antimetafísica en los filósofos políticos y morales neokantianos véase O. Höffe, Categorical Principles of Law. A Counterpoint to Modernity. Una reseña mía de este libro apareció en The Philosophical Review, vol. 114, no. 2 (2005).

Diánoia, vol. LII, no. 59 (noviembre 2007). 
Scanlon en Lo que nos debemos unos a otros. ¿Qué significa ser moral? ${ }^{4}$ En esta obra, Scanlon sigue los pasos de Rawls en varios puntos: su teoría moral es contractualista y el contrato es también hipotético, la determinación del contenido de los principios morales ocupa un lugar central, y comparte la tesis de que el sentido de los juicios morales es práctico y no metafísico. ${ }^{5} \mathrm{Mi}$ objetivo central en las páginas que siguen será examinar las razones que Scanlon ofrece para afirmar que los juicios morales son prácticos y que, por ello, no son metafísicos. En la sección 1 explicaré brevemente los rasgos centrales de la teoría de Scanlon sobre lo que él denomina "la moral de lo correcto y lo incorrecto" (the morality of right and wrong). En la sección 2 explicaré, también brevemente, qué significa que la concepción práctica de la justicia de Rawls sea práctica. Voy a sostener que la propuesta de Scanlon de una teoría moral no metafísica no puede apelar al mismo tipo de razones que Rawls ofrece para sostener que la tarea de la filosofía política debe ser práctica. Más aún, en la sección 3 sostengo que el carácter práctico de la moral no tiene por qué excluir a la metafísica, y que las razones en contra de la metafísica hay que buscarlas en otro lado. En la sección 4 concluyo que la oposición de Scanlon a la metafísica se sigue, más bien, de su rechazo al carácter categórico de las obligaciones morales y no, como él lo afirma, del carácter práctico de los juicios morales.

\section{La moral de lo correcto y lo incorrecto}

El propósito central de Lo que nos debemos unos a otros. ¿Qué significa ser moral? es ofrecer una teoría tanto del contenido como de la fuerza motivacional de un tipo particular de juicios morales, a saber, aquellos juicios sobre qué deberes morales tenemos hacia los demás. Scanlon los llama "juicios sobre lo correcto y lo incorrecto". ${ }^{6} \mathrm{La}$ "moral de lo correcto y lo incorrecto", de acuerdo con su terminología, es aquella parte de la moral a la cual pertenecen este tipo de juicios. Su propósito no es ofrecer una teoría sobre el dominio completo de la moral, sino ocuparse sólo de la parte de la moral que concierne a los deberes que tenemos hacia los demás. Scanlon deja de lado los deberes especiales que tenemos hacia personas con quienes mantenemos relaciones personales, los deberes hacia uno mismo (propios de ideales de carácter), así como los deberes que podemos tener con relación a los animales y el resto de la naturaleza. La parte de la moral de la que Scanlon se

${ }^{4}$ Todas las referencias a esta obra son a la versión en castellano.

${ }^{5}$ T. Scanlon, Lo que nos debemos unos a otros, "Introducción".

${ }^{6}$ Para un resumen de esta obra véase mi reseña en Diánoia, vol. 51, no. 57. 
ocupa podría muy bien denominarse "justicia interpersonal", en contraste con la justicia institucional. Sin embargo, debido a la influencia de la teoría de la justicia de Rawls, el término "justicia" con demasiada frecuencia se identifica con la justicia de las instituciones sociales y políticas. Al denominar la parte de la moral de la que se ocupa "lo que nos debemos unos a otros", Scanlon deja muy claro que su teoría trata de las obligaciones morales que surgen en las relaciones interpersonales no reguladas por las instituciones políticas.

Para el contractualismo de Scanlon, "un acto es incorrecto si su realización en determinadas circunstancias sería prohibida por todo conjunto de principios para la regulación general de la conducta que nadie podría rechazar razonablemente como base para un acuerdo general informado y no forzado". ${ }^{7}$ Dicho de otro modo, los actos son incorrectos cuando serían prohibidos por principios que nadie podría rechazar razonablemente. La fórmula contractualista no exige que logremos un acuerdo real con otras personas, sino que sirve de guía para el agente que se pregunta cómo debe actuar en sus relaciones con los demás. Según el contractualismo, para responder a esta pregunta debemos reflexionar sobre los principios que no podrían ser rechazados razonablemente por los demás.

Scanlon sostiene que esta fórmula contractualista establece tanto el contenido como la base normativa de la moral de lo correcto y lo incorrecto. En lo que toca al contenido, nos dice que "cuando nos planteamos la cuestión lo correcto y lo incorrecto, lo que intentamos decidir es, primero y principalmente, si determinados principios son tales que ninguna persona, motivada de la manera adecuada, podría razonablemente rechazarlos". ${ }^{8}$ En otras palabras, el acuerdo sobre los principios no es meramente un procedimiento para determinar qué deberes morales tenemos hacia otras personas; el acuerdo es, en realidad, constitutivo de estos deberes. Conforme a esta teoría, tenemos deberes hacia los demás porque hay conductas que los demás no podrían aceptar. No hay ningún hecho o valor ulterior que fundamente estos deberes y en virtud del cual los acuerdos hipotéticos podrían estar equivocados. Esto es lo que Scanlon quiere decir cuando afirma que la idea de "justificabilidad" (justifiability) frente a los demás es "básica". 9 Aunque él no lo expresa de esta manera, la fórmula contractualista es un ejemplo de lo que Rawls denomina "justicia procedimental pura". ${ }^{10} \mathrm{El}$ acuerdo

\footnotetext{
${ }^{7}$ T. Scanlon, op. cit., p. 199.

${ }^{8}$ Ibid., p. 243.

${ }^{9}$ Ibid., p. 243.

${ }^{10}$ Rawls, Teoría de la justicia, sección 14.
} 
hipotético, por sí mismo, determina el contenido de los principios morales: no hay ningún criterio independiente de lo correcto que pueda servir para evaluar los acuerdos hipotéticos y a la luz del cual estos acuerdos podrían estar equivocados. En la teoría de Scanlon, los principios son correctos si nadie puede rechazarlos razonablemente; no hay ningún criterio sustantivo con base en el cual podamos revisar este tipo de juicios morales. Desde luego, para rechazar razonablemente ciertos principios tenemos que apelar a ciertos hechos y valores. El punto aquí es que no hay ningún hecho o valor último o fundamental que el criterio de justificabilidad tenga que satisfacer.

En lo que toca a la base normativa o, como Scanlon también lo expresa, "el poder de suministrar razones" de los juicios sobre lo correcto y lo incorrecto, la fórmula contractualista captura el hecho de que cuando actuamos moralmente, nos dice, lo que nos mueve es el ideal de "ser capaces de justificar ante otros las propias acciones sobre bases que ellos no podrían rechazar razonablemente". ${ }^{11}$ Según Scanlon, el valor al que respondemos cuando actuamos por un sentido de la obligación hacia los demás es el valor de vivir con los demás en términos que podamos justificar frente a ellos. Este valor también es "básico" en cuanto fuente de la motivación para actuar moralmente. Su tesis no es que el ideal de justificabilidad frente a los demás nos mueva siempre, ya que, evidentemente, esto no es así. Pero sí sostiene que se trata de un ideal muy poderoso, y que tenemos buenas razones en favor de su influencia motivadora.

Cuando Scanlon sostiene que el ideal de justificabilidad frente a los demás es básico con relación al contenido de los juicios de lo correcto y lo incorrecto, su propósito es enfatizar que estos últimos no son juicios sobre algún valor ulterior. Para ilustrar este punto, él considera dos posturas alternativas. La primera es el utilitarismo, de acuerdo con el cual, "un acto es correcto sólo si proporciona más felicidad que cualquiera de las otras opciones disponibles en ese momento para el agente". ${ }^{12}$ Los utilitaristas, dice Scanlon, también podrían mantener que un acto es correcto si y sólo si es justificable frente a los demás en términos que ellos no podrían rechazar. Es decir, los utilitaristas podrían aceptar e incluir en su teoría el criterio contractualista. Sin embargo, la idea de justificabilidad no sería básica ya que el utilitarismo postula un valor sustantivo ulterior que sirve de criterio último para evaluar nuestros actos, a saber, la producción de un balance mayor de felicidad. En la

${ }^{11}$ T. Scanlon, op. cit., p. 200.

${ }^{12}$ Ibid., p. 243. 
propuesta de Scanlon, no hay ningún criterio independiente de corrección o de bondad que la fórmula contractualista tenga que satisfacer. Para que los principios morales sean correctos es necesario y suficiente que no puedan ser rechazados razonablemente por los demás.

Scanlon considera una segunda alternativa que presenta como una objeción al contractualismo. Esta alternativa sostiene que la idea de justificabilidad frente a los demás no puede ser básica, ya que lo básico es el valor de la vida de las personas, o como Kant lo expresa, el valor de la humanidad. De acuerdo con esta objeción, nos interesa justificar nuestras acciones frente a los demás porque apreciamos el valor que tienen los seres humanos. El meollo de esta objeción es que cuando una persona exige ser tratada de cierta manera, la fuerza de su exigencia es "independiente y anterior" a la idea de justificabilidad frente a los demás. Su exigencia se basa en el valor que ella misma tiene y que la convierte en un objeto de respeto. Según esta postura, entonces, "existe un criterio de corrección que es previo a esta noción de justificabilidad" y con relación al cual los acuerdos podrían estar equivocados. ${ }^{13} \mathrm{El}$ criterio anterior es el valor de las personas. Los acuerdos estarían equivocados en cuanto a este criterio si se establecieran principios contrarios a este valor.

Ésta es una objeción importante porque es innegable que, en nuestras prácticas morales cotidianas, la dignidad humana es un valor que sirve de criterio rector para la conducta y para los juicios morales. La respuesta de Scanlon es que la justificación de la conducta es importante porque los seres humanos tenemos la capacidad de evaluar razones y justificaciones, la cual es distintiva de los seres humanos; por ello, "el respeto adecuado hacia su valor distintivo implica tratarlos sólo de modos que ellos podrían, mediante el ejercicio adecuado de su capacidad, reconocer como justificables". ${ }^{14}$ Según esto, "la idea de justificabilidad ante otros y la idea del respeto del valor de éstos no se diferencian" porque el contenido de lo correcto y lo incorrecto no puede establecerse con independencia de lo que puede justificarse frente a los demás. ${ }^{15}$ A pesar de que Scanlon tiene razón en este último punto, el criterio de justificabilidad frente a los demás es diferente de la exigencia de respetar el valor de la humanidad: estos criterios no siempre coinciden en el contenido que los deberes establecen. Al final de la sección 4 regresaré a este punto.

\footnotetext{
${ }^{13}$ Ibid., p. 219.

${ }^{14}$ Ibid., pp. 218-219.

${ }^{15}$ Ibid., p. 221.
}

Diánoia, vol. LII, no. 59 (noviembre 2007). 
No es inusual que esta concepción procedimental de la moral se juzgue insatisfactoria. Los agentes morales con frecuencia quieren que los juicios morales traten sobre algo real, objetivo o independiente, en algún sentido, de nuestras convicciones sobre los mismos. Scanlon reconoce que algunos quisieran una caracterización más rica del "asunto del que tratan" (subject matter) los juicios sobre lo correcto y lo incorrecto. ${ }^{16} \mathrm{Si}$ el contenido de estos juicios depende sólo de lo que otros no podrían rechazar razonablemente, parece que no hay nada "real" sobre lo cual traten. Y es en este punto en que la metafísica, según Scanlon, puede resultar tentadora. Por "metafísica" él entiende la postura según la cual los juicios de lo correcto y lo incorrecto son verdaderos o falsos en la medida en que "existe algún ámbito de hechos que se supone que ellos describen, y con el que se pueden corresponder o no". ${ }^{17}$ La postura es metafísica porque apela a una "realidad metafísica de hechos morales", es decir, a una ontología de hechos morales que parece misteriosa. En coincidencia con Rawls, Scanlon afirma que su teoría de la moral no es metafísica, sino práctica. El sentido de los juicios sobre lo correcto y lo incorrecto, sostiene, no es hacer afirmaciones sobre una realidad independiente de hechos morales, sino sobre las razones que tenemos para actuar. ${ }^{18}$ Según Scalon, para que los juicios morales sean correctos es suficiente tener buenas razones para pensar que ciertas conclusiones sobre lo correcto y lo incorrecto son ellas mismas correctas. Su objetividad, afirma,

no descansa en que describan la realidad metafísica de algo independiente de nosotros, sino más bien en el hecho de que existe algo así como la reflexión correcta acerca de tales cuestiones: un procedimiento que proporciona resultados estables de los que no tenemos buenas razones para desconfiar. ${ }^{19}$

\footnotetext{
${ }^{16}$ He traducido "subject matter" como "asunto del que tratan [los juicios morales]", y no como "contenido", término usado por Ernest Weickert. El "contenido" (content) de un juicio moral es lo que el juicio expresa (p.ej., "la honestidad es una virtud"), mientras que "el asunto del que trata" es aquello a lo que se refiere (p.ej., el juicio se refiere a las razones que tenemos para considerar que la honestidad es una virtud, o bien se refiere a hechos morales independientes de nuestras razones, o bien a sentimientos que experimentamos cuando juzgamos desde un punto de vista general, etcétera).

${ }^{17}$ T. Scanlon, op. cit., p. 16.

${ }^{18}$ Ibid., p. 16.

${ }^{19}$ Ibid., p. 443.
}

Diánoia, vol. LII, no. 59 (noviembre 2007). 
Para sostener su objetividad, no tenemos que agregar que estos juicios versan sobre algo independiente de las razones que tenemos.

En las dos secciones siguientes examinaré qué entiende Scanlon por "práctico" en oposición a "metafísico". Existe un sentido general en el que cualquier teoría moral es práctica porque se ocupa de establecer criterios para guiar la conducta. Desde este punto de vista, el realismo más metafísico, en la concepción de Scanlon, también sería práctico. Pero éste no es, ciertamente, al que quiere referirse con "práctico". En este sentido general, lo práctico no se opone a lo metafísico, sino a lo teórico. La filosofía práctica se ocupa de los criterios para establecer qué acciones son buenas o correctas; la filosofía teórica, en cambio, se ocupa de los criterios para establecer qué es conocimiento y qué podemos conocer. A continuación me centraré en el sentido específico en el que Scanlon sostiene que la moralidad de lo correcto y lo incorrecto es práctica. Para ello será necesario detenernos brevemente en la postura de Rawls sobre esta cuestión, ya que fue él quien introdujo la oposición entre lo práctico y lo metafísico en la filosofía política.

\section{La concepción práctica de la justicia como equidad}

En Justice as Fairness: Political not Methaphisical ["La justicia como equidad: política no metafísica"], Rawls sostiene que los objetivos de la filosofía política no son metafísicos, sino prácticos: ${ }^{20}$

El objetivo de la justicia como equidad, en cuanto concepción política, es práctico y no metafísico ni epistemológico. Esto es, no se presenta como una concepción de la justicia que sea verdadera, sino como una concepción que puede servir de base para un acuerdo político, informado y voluntario, entre ciudadanos concebidos como personas libres e iguales. ${ }^{21}$

Una concepción de la justicia metafísica o epistemológica, de acuerdo con Rawls, sería aquella que presenta los principios de justicia como principios verdaderos de "un orden moral metafísico independiente". ${ }^{22}$ Como ejemplo de una concepción moral metafísica, él menciona el intuicionismo racional, según el cual, "los principios primeros y juicios morales, cuando son correctos, son afirmaciones verdaderas sobre un orden independiente de valores morales"; "son objeto de conocimiento

${ }^{20}$ J. Rawls, Collected Papers. Las traducciones son mías.

${ }^{21}$ Ibid., p. 394.

${ }^{22}$ Ibid., p. 395.

Diánoia, vol. LII, no. 59 (noviembre 2007). 
de la razón teórica" mediante "un tipo de percepción o intuición". ${ }^{23}$ Esta concepción es metafísica porque postula una ontología de valores morales. La postura también es epistemológica porque los juicios morales se consideran correctos o incorrectos de acuerdo con cierto conocimiento de una realidad moral independiente. La tarea de establecer los principios morales correctos se concibe, entonces, en términos epistemológicos.

En la medida en que la concepción de la justicia como equidad de Rawls no es una doctrina metafísica, los principios de justicia no pueden considerarse verdaderos en el sentido que acabo de mencionar. En tanto que tampoco se trata de una concepción epistemológica, la tarea de la filosofía política tampoco puede concebirse como la búsqueda de cierto conocimiento moral. La alternativa que él propone es que esta tarea se conciba en términos prácticos. Esto significa que la pregunta sobre los principios de justicia correctos debe verse como un problema práctico y político de acción colectiva. Conforme a esto, los principios correctos son aquellos que sirven de solución a este problema. El problema político del que Rawls se ocupa es el desacuerdo existente en la sociedad sobre los principios de justicia que deben regir las principales instituciones sociales, económicas y políticas (lo que él llama "la estructura básica"). Rawls se refiere a este problema como "la pregunta de la justicia", la cual surge en cualquier sociedad. Esta pregunta plantea qué derechos y deberes deben tener las personas en las instituciones de la estructura básica, y cómo distribuir las cargas y los beneficios de la cooperación social. ${ }^{24}$ La respuesta a esta pregunta tiene que ser un acuerdo sobre ciertos principios que determinen tanto los derechos y los deberes de las personas, como un esquema de distribución. La propuesta de concebir el objetivo de una teoría de la justicia política en términos prácticos significa, entonces, presentar los principios de justicia como una solución a un problema de acción colectiva, es decir, como la base para un posible acuerdo entre los ciudadanos.

A partir del inicio de la década de los ochenta, Rawls acotó significativamente la pregunta de la justicia de la que él se ocupa. Sostuvo que los principios de la justicia como equidad se presentan como una solución al problema de la justicia tal y como éste surge en democracias contemporáneas. Enfatizó que en este tipo de sociedades los ciudadanos difieren profundamente en las doctrinas "comprehensivas" que consideran verdaderas. Una "doctrina comprehensiva", en la termino-

${ }^{23}$ Ibid., pp. 91-92.

${ }^{24}$ J. Rawls, Teoría de la justicia, sección 2.

Diánoia, vol. LII, no. 59 (noviembre 2007). 
logía que él emplea, es una doctrina moral, ya sea religiosa o filosófica. En esta situación de pluralismo, la pregunta de la justicia se replantea del modo siguiente: ¿qué principios de justicia cabe esperar razonablemente que puedan ser aceptados por los ciudadanos, concebidos como personas libres e iguales, en una sociedad profundamente dividida por la pluralidad de doctrinas comprehensivas? Rawls sostuvo que ningún conjunto de principios de justicia que se presenten como derivados de una doctrina comprehensiva particular puede servir como solución al problema de la justicia así planteado. En particular, también sostuvo que ninguna doctrina moral metafísica, como el intuicionismo racional, puede ofrecer una respuesta capaz de resolver el desacuerdo sobre los principios de justicia que deben regir la estructura básica. Ello se debe a que no cabe esperar razonablemente que todos los ciudadanos puedan aceptar una misma doctrina moral comprehensiva o metafísica.

Podríamos pensar que, a pesar de que los ciudadanos de hecho no puedan todos aceptar una misma doctrina moral comprehensiva o metafísica, deberían aceptarla si esta doctrina resulta ser verdadera. Sin embargo, Rawls afirmó explícitamente que una concepción práctica de la justicia no debe presentarse como parte o derivada de una doctrina que se tenga por verdadera. ${ }^{25}$ La razón es que el problema práctico en cuestión es un desacuerdo sobre los principios que deben regir la estructura básica. El presentar la concepción de la justicia como verdadera no contribuye en nada a resolver el desacuerdo. Una solución adecuada al problema de la justicia, según Rawls, tendría que articularse sobre la base de ideas morales y políticas que todos los ciudadanos pueden aceptar a pesar de la diversidad de doctrinas morales que también afirman. Rawls sostuvo que su propia concepción de la justicia como equidad satisface esta condición. Afirmó que se trata de una concepción moral y política que puede ser el objeto de un acuerdo porque se basa en ideas morales y políticas que los ciudadanos ya aceptan. Estas ideas morales y políticas no son otras que la concepción democrática de los ciudadanos como personas libres e iguales, y la concepción de la sociedad como un sistema equitativo de cooperación social. Rawls sostuvo que pueden presentarse de modo que no presupongan la verdad de ninguna doctrina moral particular. La justicia como equidad, entonces, puede satisfacer la condición de aceptabilidad porque no se presenta como verdadera ni tampoco implica la negación de la verdad de ninguna otra doctrina moral comprehensiva.

${ }^{25}$ J. Rawls, El liberalismo político, Conferencia I, sección 2.

Diánoia, vol. LII, no. 59 (noviembre 2007). 
No es mi objetivo aquí evaluar la plausibilidad de la propuesta de Rawls, pero sí es necesario hacer algunas precisiones. En primer lugar, Rawls emplea dos sentidos distintos de "verdad". De un lado está la tesis de primer orden, interna del intuicionismo racional, según la cual los principios morales correctos son aquellos que resultan ser verdaderos de un orden independiente de valores morales. Del otro lado está la tesis de segundo orden según la cual una teoría moral particular, ya sea el intuicionismo racional o cualquier otra, es la doctrina moral verdadera. En aras del logro del acuerdo, Rawls está dispuesto a sacrificar estos dos sentidos de verdad moral. Los principios de justicia no pueden presentarse como verdaderos en ninguno de estos dos sentidos. ${ }^{26}$ En segundo lugar, para los fines de este artículo, es importante subrayar que, en el caso particular de Rawls, el rechazo de la metafísica está motivado por los rasgos del problema de la justicia que él aborda. $\mathrm{Su}$ queja en contra de la metafísica del intuicionismo racional no es que sea falsa. Su objeción es que esta doctrina no puede resolver el problema de la justicia en una sociedad pluralista. Como vimos, Rawls sostiene que una concepción de la justicia para una democracia moderna no puede basarse en posturas metafísicas ya que, de hacerlo, no podría ser aceptada por todos los ciudadanos. Esto deja abierta la posibilidad de que el intuicionismo racional sea verdadero. Es verdad que Rawls también piensa que el intuicionismo racional nos conduce por el camino equivocado al convertir las preguntas prácticas en problemas epistemológicos. No obstante, su objeción en contra de esta doctrina es que no puede propiciar un acuerdo político. El punto importante aquí es que la propuesta de concebir la concepción de la justicia en términos prácticos, y no metafísicos o epistemológicos, está motivada por la necesidad de articular dicha concepción de modo que no implique la falsedad de ninguna doctrina moral comprehensiva. Según Rawls, ésta es la única manera de propiciar el deseado acuerdo político. La pregunta que abordaré a continuación es si Scanlon puede apelar al mismo tipo de razones para motivar el rechazo de la metafísica en la teoría moral.

\section{3. ¿Es una concepción práctica necesariamente antimetafísica?}

Llegados a este punto no debería ser difícil apreciar que, dados los objetivos propios de una teoría moral como la de Scanlon, su afirmación

\footnotetext{
${ }^{26}$ Para una crítica de esta tesis, véase J. Raz, "Facing Diversity: The Case for
} Epistemic Abstinence", donde afirma que "no puede haber justicia sin verdad", p. 4. 
de que el sentido de los juicios morales es práctico no puede tener la misma motivación que en la teoría de Rawls. El propósito de Scanlon es ofrecer una teoría verdadera sobre el contenido y la fuente de la motivación de los juicios sobre lo correcto y lo incorrecto. A diferencia de una concepción política de la justicia, la verdad del contractualismo implica la falsedad del intuicionismo racional y del utilitarismo, para mencionar dos teorías morales alternativas. Sería absurdo sostener que el contractualismo tiene que satisfacer la exigencia de aceptabilidad desde el punto de vista de las diversas doctrinas morales que la gente afirma. Si éste fuera el objetivo, Scanlon tendría que haber desarrollado algún tipo de concepción moral "política", no una teoría moral.

La moral de lo correcto y lo incorrecto desarrollada por Scanlon es práctica en el sentido general mencionado líneas atrás, ya que se ocupa de cómo guiar la acción humana. Sin embargo, por "práctico" Scanlon entiende, además, algo mucho más específico. Nos dice que el sentido de los juicios sobre lo correcto y lo incorrecto es práctico porque "son afirmaciones acerca de lo que tenemos razón para hacer". ${ }^{27}$ El intuicionismo racional aparentemente pierde de vista este punto central cuando sostiene que los juicios sobre lo correcto y lo incorrecto se refieren a una realidad normativa independiente. El sentido específico en que la moral es práctica en el sentido de Scanlon es que sus principios son correctos sólo porque nadie podría rechazarlos razonablemente.

Al oponer "práctico" a "metafísico", Scanlon está siguiendo a Rawls; pero a diferencia de Rawls, Scanlon no puede hacer suya esta oposición sin más, dados los objetivos específicos de su propia teoría moral. Como lo mencioné al final de la sección anterior, el rechazo de Rawls de la metafísica del intuicionismo racional no apela a la falsedad de esta doctrina. Rawls no necesita mostrar tal falsedad porque su propósito es, precisamente, no disputar la posible verdad de ninguna doctrina moral comprehensiva. Por ello sólo se limita a afirmar que esta doctrina no puede resolver el problema de la justicia en sociedades contemporáneas. Scanlon, en cambio, no puede rechazar la metafísica del intuicionismo racional con el argumento de que no es necesaria para determinar qué deberes tenemos hacia los demás. Es verdad que esta metafísica no es necesaria, pero, a diferencia de la teoría de Rawls, si el contractualismo de Scanlon es la teoría moral verdadera, otras teorías alternativas tienen que ser falsas. Por ello, Scanlon tiene que ofrecer argumentos que muestren la falsedad o la falta de plausibilidad de la metafísica del intuicionismo racional. En particular, tendría que ofrecer

${ }^{27}$ T. Scanlon, op. cit., p. 16.

Diánoia, vol. LII, no. 59 (noviembre 2007). 
argumentos que muestren que esta doctrina es incapaz de hacer aquello que se propone, a saber, ofrecer una respuesta adecuada a la pregunta sobre qué nos debemos los unos a los otros. Sin embargo, Scalon no ofrece tales argumentos. Sólo se limita a señalar que no tiene por qué surgir ninguna pregunta interesante sobre la ontología de la moral si se logra caracterizar un método de razonamiento para establecer los juicios sobre lo correcto y lo incorrecto, así como también explicar por qué debemos otorgarles la importancia que usualmente les atribuimos a estos juicios.

Mi propósito aquí no es cuestionar la postura de Scanlon. Él tiene razón en que si contamos con un procedimiento para articular respuestas correctas a las preguntas sobre qué nos debemos los unos a los otros, la pregunta por la ontología de los hechos morales parece salir sobrando. En todo caso, es una pregunta que el partidario de los hechos morales tendría que motivar. Sin embargo, la pregunta que me interesa es si esta irrelevancia de la ontología moral vuelve también irrelevante la metafísica de la moral. Dicho de otro modo, la pregunta es si el sentido "práctico" de los juicios sobre lo correcto y lo incorrecto que Scanlon defiende necesariamente excluye la metafísica.

Rawls tomó la idea de una concepción "práctica" de la filosofía moral de Kant. ${ }^{28}$ De acuerdo con Kant, los principios y valores morales no son objeto de conocimiento, sino "construcciones" de la razón práctica -para usar la expresión empleada por Rawls-. Según esta postura, los principios y los valores morales no son algo que descubramos en el mundo, sino que los introducimos en él, por así decirlo. ${ }^{29}$ Lo anterior no significa que estos principios y valores sean "arbitrarios" o "subjetivos". Kant sostiene que es posible establecer criterios de la razón práctica para determinar qué valores y principios son correctos y se les puede llamar propiamente "morales". El criterio fundamental es el imperativo categórico, el cual es un principio objetivo de la razón práctica porque es necesario para la voluntad de un ser racional finito. ${ }^{30}$ En la interpretación de Rawls, este principio moral fundamental establece un procedimiento para determinar según qué principios debemos actuar. Este principio exige, en su primera formulación, que actuemos según máximas que podamos querer como leyes universales. Por ello, Rawls sostiene, el procedimiento para determinar los principios según los cua-

\footnotetext{
${ }^{28}$ J. Rawls, "Kantian Constructivism in Moral Theory", en Collected Papers, p. 306.

${ }^{29}$ Véase C. Korsgaard, Las fuentes de la normatividad, capítulo 4.

${ }^{30}$ I. Kant, Fundamentación de la metafísica de las costumbres, capítulo 3.
} 
les debemos actuar consiste en un ejercicio de "universalización". ${ }^{31}$ La tesis metaética es que los principios y los valores morales son el resultado de un procedimiento de construcción de la razón práctica: no los encontramos en el mundo; los "construimos" conforme al imperativo categórico. De acuerdo con esto, no hay principios ni valores morales independientes de la legislación de la razón práctica.

En la teoría de Kant, entonces, además de prácticos en el sentido general de ser guías para la acción, los principios morales son también prácticos en un sentido más específico, a saber, porque son construcciones de la razón práctica. La justificación de estos principios, según esto, depende solamente de que queden plenamente establecidos desde el punto de vista de la razón práctica. Esta tesis constructivista sobre la naturaleza de los principios morales se opone claramente a la postulación de una ontología de hechos morales independientes. No obstante, el constructivismo moral está muy lejos de oponerse a la metafísica. Al contrario, según Kant, sólo cuando la razón se concibe en términos prácticos, es decir, como el poder de producir objetos mediante ideas, nos encontramos en el camino correcto de la metafísica. ${ }^{32}$

Lo que caracteriza a la metafísica, según Kant, es que busca lo "incondicionado" tanto en términos especulativos como prácticos: busca una explicación completa del mundo y una justificación completa de la acción humana. En su teoría, las preguntas morales sobre qué debemos hacer nos conducen inevitablemente a la metafísica porque, según él, la razón humana sólo puede quedar satisfecha con principios para los cuales existe una justificación completa. ${ }^{33}$ La pregunta por una justificación completa no es más que la pregunta por lo incondicionado. Kant sostiene que sólo podemos lograr esta justificación cuando mostremos que hay un principio de acción que es vinculante para nosotros de manera incondicionada. Dicho principio expresaría o contendría también un valor incondicionado o absoluto. Kant afirma que mientras que la razón especulativa se vuelve dialéctica en su búsqueda de lo incondicionado, la razón práctica sí encuentra lo incondicionado en las ideas

${ }^{31}$ En Rivera Castro, "Moral Principles and Agreement", sostengo que el procedimiento de universalización no debe entenderse como una prueba encaminada al logro del acuerdo.

${ }^{32}$ I. Kant, Crítica de la razón práctica, libro segundo ("Dialéctica de la razón pura práctica"), capítulo segundo ("De la dialéctica de la razón pura en la determinación del concepto del bien supremo"), sección 7 "Cómo sea posible pensar una ampliación de la razón pura en sentido práctico sin que por ello al mismo tiempo se amplíe su conocimiento como razón especulativa".

${ }^{33}$ I. Kant, Crítica de la razón pura, prólogo de la primera edición. 
morales. En particular, Kant sostiene que la razón práctica es capaz de establecer valores incondicionados (a los que llamamos "morales"). La tesis de que existe algo con valor absoluto o incondicionado es, entonces, una afirmación metafísica en el sentido de Kant.

El punto que me interesa destacar es el siguiente: el que una concepción de la moral sea práctica no significa que tenga que excluir a la metafísica. La postulación de una ontología de hechos morales independientes es una manera de concebir la metafísica de la moral, pero no la única. Esta postulación es una postura metafísica porque plantea una justificación última de los juicios morales, a saber, su correspondencia con hechos morales independientes. Otra manera de concebir la metafísica de la moral es en términos prácticos, es decir, con base en algún principio último o algún valor absoluto como el imperativo categórico kantiano y el valor de la humanidad como fin en sí mismo. Lo que ambas posturas metafísicas comparten, y en virtud de lo cual son propiamente "metafísicas", es la idea de que la justificación de los juicios morales tiene que ser completa, última o incondicionada. ${ }^{34}$ Por lo tanto, para rechazar la metafísica de la moral en general lo que habría que negar es la necesidad de articular este tipo de justificación. Si pensamos que no es necesaria una justificación última o completa, entonces no habrá necesidad de la metafísica práctica. ${ }^{35}$ Pero para rechazar la metafísica de la moral de esta manera, no sirve de nada apelar al sentido práctico de los juicios morales. Las consideraciones en favor del carácter práctico de la moral no constituyen razones en contra de la metafísica; estas razones hay que buscarlas en otro lado.

\section{4. ¿Es la moral categórica?}

Para entender por qué alguien querría rechazar la necesidad de buscar una justificación última o completa de los juicios morales y, con ello, la necesidad de la metafísica de la moral, primero es necesario averiguar por qué alguien querría buscar semejante justificación. En la teoría de Kant, la metafísica de la moral es necesaria e inevitable porque, de acuerdo con él, la moral es categórica. Lo que distingue el valor moral del resto de los valores es su carácter incondicionado o absoluto. Por ello, es un tipo de valor que nunca debe quedar subordinado a ningún otro. Según Kant, nuestras prácticas y creencias morales cotidia-

${ }^{34}$ C. Korsgaard, op. cit., pp. 49-50.

${ }^{35}$ Aquí estoy usando el término "metafísica" en el sentido más tradicional y estricto que mencioné en la introducción. 
nas revelan que les atribuimos un carácter categórico a las exigencias morales. Kant sostiene que el valor absoluto o incondicionado es una propiedad de la "humanidad", la cual es nuestra capacidad racional de proponernos fines. La "dignidad" es el nombre con el cual nos referimos a este tipo de valor. Debido a que la humanidad tiene valor absoluto o incondicionado, es fuente de obligaciones categóricas sobre cómo nos debemos relacionar con los seres capaces de proponerse fines mediante la razón; en particular nos exige que siempre la tratemos (a la humanidad) como un fin, nunca como un mero medio.

La pregunta sobre si la moral es o no categórica resulta central en la filosofía moral contemporánea. Otfried Höffe ha sostenido, recientemente, que la cultura moderna está dividida en cuanto a este punto: por un lado, una actitud pragmática inclina el balance en favor de algún tipo de consecuencialismo; por el otro, el discurso de los derechos humanos muestra un profundo compromiso con las obligaciones categóricas. Uno de los ejemplos que ofrece es el deber categórico de no castigar a los inocentes. ${ }^{36}$

El contractualismo de Scanlon puede verse como un intento por alejarse de la concepción categórica de la moral sin caer en el consecuencialismo. Esta especie de propuesta "intermedia" es muy oportuna ya que, durante varias décadas, las dos alternativas en teoría moral han sido el kantismo y alguna versión del consecuencialismo (usualmente el utilitarismo). ${ }^{37}$ Quienes se inclinan por alguna forma de kantismo con frecuencia rechazan las obligaciones categóricas ya que es difícil coincidir con Kant en que nunca puede ser correcto contrarrestar el mal moral en el mundo recurriendo a la coacción, la fuerza y la mentira. En el famoso ejemplo que él ofrece, sería inmoral mentirle a un asesino potencial con el fin de salvar a su posible víctima. ${ }^{38} \mathrm{El}$ valor incondicionado de la humanidad implica que nunca puede ser moralmente bueno tratar a una persona como un mero medio, aun cuando la persona en cuestión emplee su capacidad racional para la procuración de fines malvados. Aunque seguramente la mayoría de nosotros elegiría recurrir a la mentira, la fuerza o la coacción en un caso extremo como el del ejemplo de Kant, es importante notar que no sería apropiado tratar

${ }^{36}$ O. Höffe, op. cit., p. 161.

${ }^{37}$ Contrario a lo que muchos piensan, no creo que la ética de la virtud constituya una tercera alternativa. Una teoría de la virtud no nos dice cuál es el origen del valor moral ni tampoco cómo justificar los principios morales. Una teoría de este tipo se ocupa de decirnos qué significa ser virtuoso y cómo podemos llegar a serlo.

${ }^{38}$ Este ejemplo es una referencia al ejemplo que Kant presenta en "Sobre un supuesto derecho de mentir por filantropía”.

Diánoia, vol. LII, no. 59 (noviembre 2007). 
de justificar la acción afirmando que, en este caso particular, mentir era moralmente correcto. Mentir es inmoral porque, al hacerlo, tratamos a la humanidad del otro como un mero medio. Precisamente porque la mentira, la coacción y la fuerza son inmorales en las relaciones interpersonales, las acciones inmorales de los otros nos dejan moralmente vulnerables, ya que nos empujan a actuar de manera inmoral para defendernos o para defender a otras personas. ${ }^{39}$ En la moral categórica de Kant, las acciones moralmente malvadas son fuente de dilemas morales para los demás. ${ }^{40}$

En una teoría utilitarista, en cambio, las acciones son moralmente correctas cuando maximizan ciertos bienes, tales como el placer, la felicidad del mayor número o la satisfacción de las preferencias. Por ello, en una teoría de este tipo sería moralmente correcto recurrir a la coacción, la fuerza o el engaño si de esta manera se promueve la felicidad del mayor número. Sin embargo, el utilitarismo también tiene desventajas importantes porque no puede establecer valores absolutos ni prohibiciones categóricas. Por ejemplo, castigar a un inocente puede ser moralmente correcto si contribuye a promover el bienestar de la mayoría. El utilitarismo también nos coloca en las manos de los demás, aunque de otra manera: como no puede justificar la dignidad de los seres humanos como un valor absoluto, justifica que seamos tratados

${ }^{39}$ En un intento por hacer inteligibles estas consecuencias aparentemente inaceptables, Korsgaard sostiene que el agente moral kantiano tiene que concebirse a sí mismo como miembro de un posible reino de los fines en la tierra. Tal reino es un ideal moral en el cual todos respetan a la humanidad como un fin en sí mismo. El agente moral contribuye a la realización de este ideal cada vez que actúa de maneras que son moralmente buenas. El problema, sin embargo, es que el mundo en el que vivimos no es un reino de los fines, puesto que, de hecho, mucha gente procura fines malvados. El mundo real se encuentra muy lejos de este ideal moral. La pregunta, entonces, es cómo lidiar con el mal moral: hemos de actuar de manera inmoral violando obligaciones categóricas en aras de producir buenas consecuencias, o hemos de hacer la parte que nos toca en la realización del ideal moral del reino de los fines actuando moralmente, sean cuales sean las consecuencias. Es muy probable que la gran mayoría de la gente elegirá actuar inmoralmente con el fin de producir buenas consecuencias en situaciones de este tipo por atractivo que sea el ideal del reino de los fines. Véase su artículo "The Right to Lie: Kant on Dealing with Evil", en Creating the Kingdom of Ends.

${ }^{40}$ Esto no significa que, según Kant, la coacción nunca esté justificada moralmente. En su teoría del derecho se ocupa precisamente de las condiciones bajo las cuales es posible justificar la coacción con el fin de impedir que la gente procure la realización de fines que amenazan el ejercicio de la libertad de acción de los demás. Desarrollo este punto en Rivera Castro, "La distinción entre derecho y moral en el pensamiento de Kant". 
como meros medios siempre que ello sea necesario para la producción del mayor bienestar del mayor número.

El contractualismo de Scanlon no es consecuencialista porque nunca afirma, al menos no directamente, que la moral exija maximizar el bien a través de nuestras acciones. Es posible que, en ciertas ocasiones particulares, el criterio contractualista establezca un principio moral que exija la producción de las mejores consecuencias, pero esto dependerá de las razones que se tengan. Igualmente, también puede ser que, en un caso particular, el criterio contractualista establezca un principio que prohíba algún tipo de conducta, como castigar a un inocente, aunque dicho castigo pudiese contribuir a la maximización del bienestar del mayor número. Pero esto, de nuevo, dependerá de las razones que se tengan. El contractualismo, por sí mismo, no se compromete con las obligaciones categóricas. En lugar de ello, es una postura intermedia entre el consecuencialismo y el kantismo: por un lado, las consecuencias se toman en cuenta en el momento de reflexionar qué es lo que otros podrían rechazar razonablemente; por el otro, nos exige que actuemos de maneras que puedan estar justificadas frente a los demás.

Se podría pensar que la exigencia de justificabilidad frente a los demás es categórica en el sentido de que nunca puede ser bueno actuar de maneras que no puedan ser justificables frente a los demás. Sin embargo, Scanlon no presenta el contractualismo de esta manera. Se limita a afirmar que el ideal de justificabilidad es muy poderoso y que tenemos razones para inclinaros por él. Nunca dice que sea una obligación absoluta guiarnos por él. Más aún, para sostener que un valor o un principio de acción es categórico es necesario establecerlo de alguna manera. Cuando Kant sostiene que hay un imperativo categórico, su tesis es que hay un principio de acción que es necesario para nosotros en el sentido de que no podemos actuar sin guiarnos de alguna manera por él. Según Kant, la acción humana es tal que siempre actuamos según máximas, las cuales son leyes universales para el agente aunque no siempre se verifique que efectivamente puedan servir de leyes universales para todos. De manera similar, Kant sostiene que la humanidad es algo que necesariamente valoramos en nosotros mismos aunque no siempre lo hagamos apropiadamente ni tampoco la valoremos siempre en la persona de los demás. Para que un principio o valor sea categórico, entonces, no es suficiente decir que lo es: es necesario mostrar que efectivamente es incondicionado para nosotros.

Mi conclusión, entonces, es que Scanlon rechaza la metafísica de la moral en general, y no sólo la metafísica de una ontología de hechos 
morales, debido a su concepción no categórica de la moral. En consecuencia, nunca sostiene que las consideraciones morales deban siempre tener primacía sobre otros valores, aunque sí afirma que usualmente la tienen. En ejemplos paradigmáticos, como cumplir las promesas o no mentir, Scanlon afirma que no puede haber obligaciones absolutas de observar este tipo de conductas. Qué debamos hacer, nos dice, dependerá de las características de la situación.

En conformidad con su rechazo de la metafísica, Scanlon piensa que no es necesario buscar una justificación completa que apele a valores últimos o incondicionados. Afirma que la noción de "razón" puede considerarse "primitiva" en el sentido de que no necesita ninguna explicación. ${ }^{41}$ Desde una perspectiva kantiana, esto equivale a detener la búsqueda de lo incondicionado en este punto. Al tomar la noción de razón como primitiva, Scanlon se rehúsa a continuar indagando si las razones que tenemos en favor o en contra de ciertos principios morales pueden ellas mismas fundarse en algún otro principio o valor más fundamental a cuya luz puedan ser evaluados. Aunque no es mi objetivo determinar aquí si esta postura es plausible o no, sí me interesa señalar que la renuencia a buscar una justificación completa que apele a valores últimos nos da la pauta para identificar sus razones en contra de la metafísica. Al rechazar la necesidad de buscar una justificación completa o última de los juicios morales, Scanlon renuncia a la búsqueda de algún valor último en el cual se funden las exigencias morales. En mi opinión, la renuencia de Scanlon a buscar una justificación última de la moral es la contrapartida de su rechazo de las obligaciones categóricas. Esto es lo que motiva su rechazo de la metafísica.

Para concluir quiero retomar un punto que dejé pendiente en la sección 1 . A pesar de rechazar el carácter categórico de las exigencias de la moral de lo correcto y lo incorrecto, Scanlon también afirma que actuar de maneras que otros no puedan rechazar razonablemente es lo mismo que respetar lo que Kant llama "humanidad". Esto resulta sorprendente porque, si tal equivalencia se sostiene, tal vez el contractualismo tendrá que aceptar las obligaciones categóricas y, por lo tanto, la metafísica. Scanlon hace esta afirmación en respuesta a la objeción según la cual la justificabilidad no puede ser básica, sino que lo básico es el valor de la vida humana. ${ }^{42}$ De acuerdo con esto, nos importa justificar nuestras acciones frente a los demás debido a que valoramos la capacidad de la gente para evaluar razones. La respuesta de Scanlon es que la justifica-

${ }^{41}$ T. Scanlon, op. cit., p. 33.

${ }^{42}$ Véase la sección 1. 
bilidad frente a los demás es lo mismo que respetar el valor de la humanidad porque el respeto adecuado hacia el valor distintivo de los seres humanos "implica tratarlos sólo de modos que ellos podrían, mediante el ejercicio adecuado de su capacidad, reconocer como justificables". ${ }^{43}$ El problema con esta respuesta es que la idea de justificabilidad frente a los demás, tal y como Scanlon la entiende, es una manera, entre otras, de interpretar la exigencia de respetar la capacidad racional práctica de los seres humanos, es decir, la capacidad de proponernos fines y de ofrecer razones y justificaciones. Estas dos ideas no son, en modo alguno, idénticas.

En la teoría de Kant, respetar la humanidad es respetar la capacidad de las personas para elegir sus propios fines independientemente de que esta capacidad se ejerza de maneras que consideramos razonables. El punto es crucial para rechazar el paternalismo y defender la autonomía individual. En la interpretación de Kant, el respeto hacia la capacidad racional práctica de los seres humanos debe ser incondicionado: debemos respetar la capacidad de las personas de elegir sus propios fines independientemente de si aprobamos o reprobamos las elecciones específicas que hagan. Como ya lo mencioné, esta exigencia puede colocarnos en situaciones moralmente difíciles, de modo que las acciones inmorales de otros nos empujen a actuar nosotros mismos de manera inmoral. Pero esto es lo que se sigue de la exigencia categórica de respetar la capacidad para la autonomía como un valor absoluto.

El contractualismo de Scanlon, en cambio, exige respetar ciertos ejercicios de la capacidad para la autonomía, pero no todos: debemos respetar las acciones y las decisiones de los demás sólo en la medida en que las consideremos razonables. Si alguien se comporta de una manera que no consideramos razonable, el contractualismo sostiene que no tenemos ninguna obligación, en principio, de no interferir. Según esta teoría, las razones de los demás cuentan sólo en la medida en que los demás las consideran razonables. El respeto hacia la capacidad racional práctica de los demás queda condicionado, por lo tanto, a que esta capacidad se ejerza de manera razonable. Debido a esta condición, la justificabilidad resulta ser más básica que respetar la capacidad de elección de los demás. Por ello, no puede haber obligaciones categóricas en esta teoría, lo cual, a su vez, explica por qué el contractualismo no necesita la metafísica. Qué debamos hacer, según el contractualismo, dependerá de las razones que nosotros tengamos, de las razones que

${ }^{43}$ T. Scanlon, op. cit., pp. 218-219.

Diánoia, vol. LII, no. 59 (noviembre 2007). 
pensemos que los demás tienen, y de si consideramos estas razones razonables. Todo el peso recae en la idea de "razonabilidad" y en nuestra capacidad para determinar qué es razonable y qué no.

De acuerdo con el contractualismo, si consideramos que el asesino potencial del ejemplo de Kant actúa según un principio que los demás podrían rechazar razonablemente, mentirle no será moralmente incorrecto. Ésta es, desde luego, una implicación positiva; pero antes de alegrarnos es importante reflexionar en torno a que no todas las personas cuyas acciones consideramos irrazonables son asesinos potenciales. En mi opinión, es perturbador que las razones de los demás tengan peso moral sólo en la medida en que las consideremos razonables. En la teoría de Kant, las acciones irrazonables o hasta malvadas de los demás nos plantean problemas morales, porque la capacidad de elección individual tiene valor incondicionado y no podemos obviarla en nuestras acciones. En el contractualismo, en cambio, las acciones irrazonables o malvadas de los otros no nos plantean ninguna dificultad moral. En esta teoría, tales acciones resultan ser un obstáculo con el que hay que lidiar. Las acciones malvadas no representan ninguna amenaza moral para las personas razonables. En la república moral de los razonables, la gente irrazonable se queda fuera.

Al mostrar que la idea de justificabilidad es una interpretación de la exigencia de respetar el valor de la humanidad sin ser idéntica a este último, no pretendo en modo alguno sugerir que el contractualismo es menos atractivo que la moral kantiana. Mi propósito es señalar una diferencia importante entre la teoría de Scanlon y la de Kant: mientras que esta última se compromete con las obligaciones categóricas, la primera no lo hace. Ésta es la razón, como ya vimos, por la cual el contractualismo no necesita la metafísica. Si pensamos que la moral es categórica, la metafísica será necesaria aunque pensemos, al mismo tiempo, que la moral es práctica. La pregunta que queda por resolver es si la moral es categórica. Ésta es una cuestión central en filosofía moral, ya que concierne a la naturaleza de las exigencias morales. No se trata de una mera especulación que la ética debería dejar de lado con el fin de centrarse en preguntas de contenido. Si resulta que hay exigencias morales categóricas, entonces la ética no podrá proceder sin la metafísica. 


\section{BIBLIOGRAFÍA}

Habermas, Jürgen, Justification and Application. Remarks on Discourse Ethics, trad. Ciaran Cronin, The MIT Press, Cambridge, Mass., 1993.

— xico, 1990.

Höffe, Otfried, Categorical Principles of Law. A Counterpoint to Modernity, trad. Mark Migotti, The Pennsylvania State University Press, Pensilvania, 2002.

Hume, David, Tratado de la naturaleza humana, trad. Félix Duque, Tecnos, Madrid, 1988.

Kant, Immanuel, Crítica de la razón práctica, trad. Dulce María Granja, Universidad Autónoma Metropolitana/Porrúa, México, 2001.

—. Critica de la razón pura, trad. Pedro Ribas, Alfaguara, Madrid, 1984.

_- Fundamentación de la metafísica de las costumbres, 6a. ed., trad. Manuel García Morente, Porrúa, México, 1986.

— berto Rodríguez, Tecnos, Madrid, 1993.

Korsgaard, Christine, Creating the Kingdom of Ends, Cambridge University Press, Cambridge, 1996.

— L Las fuentes de la normatividad, trad. Laura Lecuona y Laura Manríquez, Instituto de Investigaciones Filosóficas-UNAM, México, 2000.

O’Neill, Onora, “Constructivism vs. Contractualism”, Ratio, vol. 16, no. 4, 2003, pp. 319-331.

Rawls, John, Collected Papers, ed. Samuel Freeman, Harvard University Press, Cambridge, Mass., 1999.

— El El liberalismo político, trad. Antoni Doménech, Crítica, Barcelona,1996.

_- "Justice as Fairness: Political not Metaphysical", Philosophy and Public Affairs, vol. 14, 1985, pp. 223-252. (Reimpreso en Collected Papers, pp. 388 414.)

_- "Kantian Constructivism in Moral Theory", Journal of Philosophy, vol. 77, 1980, pp. 515-572. (Reimpreso en Collected Papers, pp. 303-358.)

— Económica, México, 1978.

Raz, Joseph, "Facing Diversity: the Case for Epistemic Abstinence", Philosophy and Public Affairs, vol. 19, 1990, pp. 3-46.

Rivera Castro, Faviola, "La distinción entre derecho y moral en el pensamiento de Kant", Revista Latinoamericana de Filosofía, vol. 27, no. 2, 2001, pp. 335359. (Reimpreso en Virtud y justicia en Kant, capítulo 3.)

__, "Moral Principles and Agreement", Crítica, vol. 32, no. 94, 2000, pp. 4388. (Reimpreso en Virtud y justicia en Kant, capítulo 4.)

— Virtud y justicia en Kant, Fontamara, México, 2003.

Scanlon, Thomas, "Precis of What We Owe to Each Other", Philosophy and Phenomenological Research, vol. 66, no. 1, 2003, pp. 159-161.

_., "Thickness and Theory", The Journal of Philosophy, vol. 100, no. 6, 2003, pp. 275-287.

Diánoia, vol. LII, no. 59 (noviembre 2007). 
Scanlon, Thomas, What We Owe to Each Other, Harvard University Press, Cambridge, Mass., 1998. [Versión en castellano: Lo que nos debemos unos a otros. ¿Qué significa ser moral?, trad. Ernest Weikert García, Paidós, Barcelona, 2003.]

Timmons, Mark, "The Limits of Moral Constructivism", Ratio, vol. 16, no. 4, 2003, pp. 391-423.

Wallace, Jay, "Scanlon's Contractualism", Ethics, vol. 112, 2002, pp. 429-470.

Recibido el 1 de mayo de 2006; aceptado el 31 de enero de 2007. 